\title{
Gibeleko erradioenbolizazioaren CFD simulazioak: odolaren biskositatearen eragina gibeleko hemodinamikan eta mikroesferen banaketan
}

\author{
(CFD simulations of liver radioembolization: the effect of blood \\ viscosity on liver hemodynamics and microsphere distribution)
}

\author{
Unai Lertxundi ${ }^{1 *}$, Jorge Aramburu ${ }^{1}$, Raúl Antón ${ }^{1,2}$, Jose Ignacio Bilbao ${ }^{2,3}$, \\ Macarena Rodríguez-Fraile ${ }^{2,4}$, Bruno Sangro ${ }^{2,5}$ \\ ${ }^{1}$ Ingeniaritza Mekanikoa eta Materialak Saila, TECNUN Ingeniaritza Eskola, \\ Nafarroako Unibertsitatea \\ 2 IdiSNA, Nafarroako Osasun Ikerkuntzako Institutua, \\ ${ }^{3}$ Erradiologia Saila, Nafarroako Unibertsitateko Klinika, \\ ${ }^{4}$ Medikuntza Nuklearra Saila, Nafarroako Unibertsitateko Klinika, \\ ${ }^{5}$ Gibelaren Unitatea eta CIBEREHD, Nafarroako Unibertsitateko Klinika,
}

LABURPENA: Erradioenbolizazioa (RE) gibeleko minbizia tratatzeko metodoetako bat da. Bertan, mikrokateter bidez gibeleko arterian mikroesfera erradioaktiboak injektatzen dira, tumoreei enbolizazio eta erradiazio bidez erasotzeko. Mikroesferen ibilbidea ordenagailu bidezko fluido dinamikako simulazioekin (CFD) azter daiteke. Kalkulu horien iraupen luzea arazo bat da medikuntzaren egunerokotasunean simulazioak erabili ahal izateko. Kalkuluak azkartzeko asmoz, odolaren biskositatearen izaera ez-newtondarra izaera newtondarrera sinplifikatu da. Emaitzek erakutsi dute mikroesferen banaketan eta odolaren hemodinamikan biskositate aldakorraren eragina baztergarria dela, odola fluido newtondar gisa aztertzearen sinplifikazioa ontzat emanez.

HITZ GAKOAK: Erradioenbolizazioa, gibeleko minbizia, odolaren biskositatea, fluido newtondar eta ez-newtondarrak.

ABSTRACT: Radioembolization (RE) is a treatment for patients with liver cancer. RE consists of the infusion of radioactive microspheres in the hepatic artery using a microcatheter. Microspheres treat tumors by embolization and radiation. The trajectory of the microspheres can be analyzed using computational fluid dynamics simulations (CFD). The long duration of these calculations supposes a problem for their use in the clinical setting. To decrease the simulation time, blood, a non-Newtonian fluid, was considered as a Newtonian fluid. Results show that microsphere distribution and blood flow characteristics barely change when using a Newtonian fluid approach vs. a non-Newtonian fluid approach.

KEYWORDS: Radioembolization, liver cancer, blood viscosity, Newtonian and no-Newtonian fluids.

\footnotetext{
* Harremanetan jartzeko / Corresponding author: Unai Lertxundi. Ingeniaritza Mekaniko eta Materialen Departamentua, TECNUN Escuela de Ingeniería, Universidad de Navarra, Manuel Lardizabal Ibilbidea, 13 (20018 Donostia, Gipuzkoa). ulertxundi@tecnun.es - https://orcid.org/0000-0002-8729-2717
}

Nola aipatu / How to cite: Lertxundi, Unai; Aramburu, Jorge; Antón, Raúl; Bilbao, Jose Ignacio; Rodríguez-Fraile, Macarena; Sangro, Bruno (2022). "Gibeleko erradioenbolizazioaren CFD simulazioak: odolaren biskositatearen eragina gibeleko hemodinamikan eta mikroesferen banaketan». Ekaia, 42, 2022, 339-348. (https://doi.org/10.1387/ekaia.23082).

Jasotze-data: 2021, irailak 24; Onartze-data: 2021, irailak 24.

ISSN 0214-9001 - elSSN 2444-3255 / (c) 2022 UPV/EHU

(7) $\odot$ Lan hau Creative Commons Aitortu-EzKomertziala-LanEratorririkGabe 4.0 Nazioartekoa lizentzia baten mende dago 
Unai Lertxundi, Jorge Aramburu, Raúl Antón, Jose Ignacio Bilbao, Macarena Rodríguez-Fraile, Bruno Sangro

\section{SARRERA ETA MOTIBAZIOA}

Gaur egungo arazoei aurre egiteko diziplinarteko taldeak sortzeko joera nabaria da, arlo ezberdinetako espezialisten elkarlanaz baliatuz. Gaixotasun larriei aurre egiteko garaian ere ez da gutxiagotan gertatzen. Minbiziaren aurkako tratamenduetan adibidez erradiologo interbentzionistek, erradiologo onkologoek, hepatologoek eta beste aditu batzuek hartzen dute parte. Tratamendu horietako bat erradioenbolizazioa da, non mikroesfera erradioaktiboak arteria hepatikoan injektatzen diren tumoreei soilik erasotzeko helburuarekin.

Tratamendua konplexua da oso. Prozedurak izan ditzakeen gorabeherak argitzeko asmoz, ordenagailu bidez, fluidoen dinamika aztertzen da zenbakizko simulazioak eginez (computational fluid dynamics, CFD). Era horretan, injektatutako mikroesferek odol-fluxuan zehar jarraitzen duten ibilbidea aztertzen da, azken batean tratamenduaren efizientzia handitzeko asmoarekin.

Lan honen motibazioa zera da: minbiziaren inguruan sortzen diren diziplinarteko taldeetan ingeniariek egin ditzaketen ekarpenak plazaratzea eta ingeniaritzan erabilitako erreminten bidez medikuek izan ohi dituzten galderei erantzunak.

\section{ARLOKO EGOERA ETA IKERKETAREN HELBURUAK}

Gibeleko minbizia mundu mailan hedatuenetarikoa da bai intzidentziari bai hilkortasun-tasari dagokienez [1]. Hainbat tratamendu aurkitu dira minbizi hau sendatzeko, eta, horien artean, erradioenbolizazioa (RE) dago. RE metodo bikoitz bat da. Alde batetik, enbolizazioaren bidez tumoreak elikatzen dituzten odol-hodiak ixtea du helburu. Bestetik, energia erradioaktiboa modu selektibo batean aplikatzen da, minbizidun ehunetan soilik aplikatuz, printzipioz. Mikrokateter bidez, itrio-90 $\left.{ }^{90} \mathrm{Y}\right)$ erradiazio-dosi tumorizida handia duten mikroesferak injektatzen dira arteria hepatikoan, baina gibeleko parenkima osasuntsu mantenduta (ikus 1. irudia).

Tratamendu honen gakoa mikroesfera erradioaktiboak minbizidun ehunetara soilik iristea da, gibeleko ehun osasuntsua tratamenduarekin ez kaltetzeko. Horretarako, berebiziko garrantzia du mikroesferen ibilbidea aurreikusteak, injekzio-baldintzak ondo finkatu ahal izateko. Horrenbestez, lehen esan bezala, ordenagailu bidezko kalkuluak egiten dira. Hainbat ikerketa garatu dira azken hamarkadan RE bitarteko gibeleko hemodinamika (odolaren dinamika) eta mikroesferen garraioa aztertzen dutenak. 

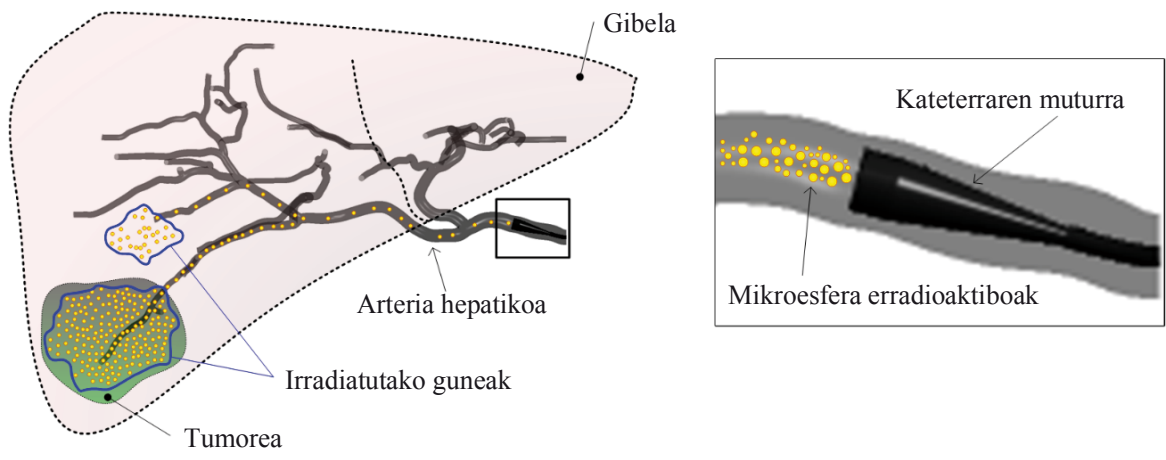

1.irudia. Gibeleko erradioenbolizazioa, eskematikoki.

Kalkulu horiek guztiak, ordea, denbora asko eskatzen dute. Haien helburu nagusia arlo honetako medikuei RE planifikatzeko garaian erabakiak hartzen laguntzea izanik, kalkuluen iraupena biziki laburtu beharra dago, benetan erabilgarriak izatea nahi bada. Kalkulu-denbora gutxitzen duten hainbat ikerketa gauzatu dira. Beste askoren artean, Childress eta Kleinstreuer-ek arterien malgutasunaren eragina aztertu dute, eta odol-hodiak zurrunak balira bezala azter zitezkeela ondorioztatu. Sinplifikazio horrek ez du errore handirik gehitzen, eta kalkulu-denbora izugarri gutxitzen du [2]. Bestalde, Lertxundi et al.-ek geometrian egindako sinplifikazioak aztertu dituzte, eta hala emaitzen zehaztasuna mantendu eta kalkulu-denbora \% 60 inguru gutxitu [3].

\section{IKERKETAREN MUINA}

Artikulu honetan, garatu beharreko kalkulu eta simulazioak sinplifikatzeko asmoz, odolaren biskositatearen eragina aztertuko da. Errealitatean odolak biskositate aldakorra du (hau da, fluido ez-newtondarra) hainbat aldagaik eraginda: abiadurak, tenperaturak, zizailadura-esfortzuak, eta abar. Hainbat ikerketak jokabide hori kontuan izaten dute simulazioak egiterakoan $[4,5]$. Bestalde, biskositate baliokide konstante bat ere erabil daiteke fluido newtondarra balitz bezala aztertuz [6]. Gure taldearen ordenagailu bidezko kalkuluak gehiago sinplifikatzeko asmoz eta Rocali-ren taldearen hurbilketaz baliatuz [6], odola fluido ez-newtondar edo newtondar gisa aztertzearen ezberdintasunak ikertu dira.

\subsection{Eredu matematikoa eta simulazioak}

Couinaud-en arabera [7], gibela zortzi segmentuz dago osatuta (S1, $\mathrm{S} 2, \ldots, \mathrm{S} 8$ ). Hiru pazienteren kasuak aztertu dira ikerketa honetan. He- 
Unai Lertxundi, Jorge Aramburu, Raúl Antón, Jose Ignacio Bilbao, Macarena Rodríguez-Fraile, Bruno Sangro

mendik aurrera, 1 pazientea, 2 pazientea eta 3 pazientea deituko zaie. Simulazioak egiteko, pazienteen beren arteria hepatiko sareak erabili dira, MeVis (MeVis Medical Solutions AG, Bremen, Alemania) softwarearen bidez lortuak. Hiru kasuetan fikziozko minbizi-egoera bera sortu da. Egoera hori 8 segmentuan (S8) dagoen kartzinoma hepatozelular batean (HCC, hepatocellular carcinoma) datza. Tumorearen bolumena S8-ko ehun osasuntsuaren \% 20 dela kontsideratu da. Segmentu bakoitzaren bolumenak ere $\mathrm{MeV}$ is softwarearen bidez lortu dira. Arteria-sare osoa erabili beharrean, Lertxundi et al. lanean adierazitakoaren baitan moztuko dira geometriak [3]. Ondorengo irudian (ikus 2. irudia), erabilitako hiru pazienteen arteria hepatiko sareak ikus daitezke. Gainera, mikrokateterraren kokapena, tumoreen kokapena eta arteria-adar bakoitzak odola zer segmentutara eramaten duen daude definituak.
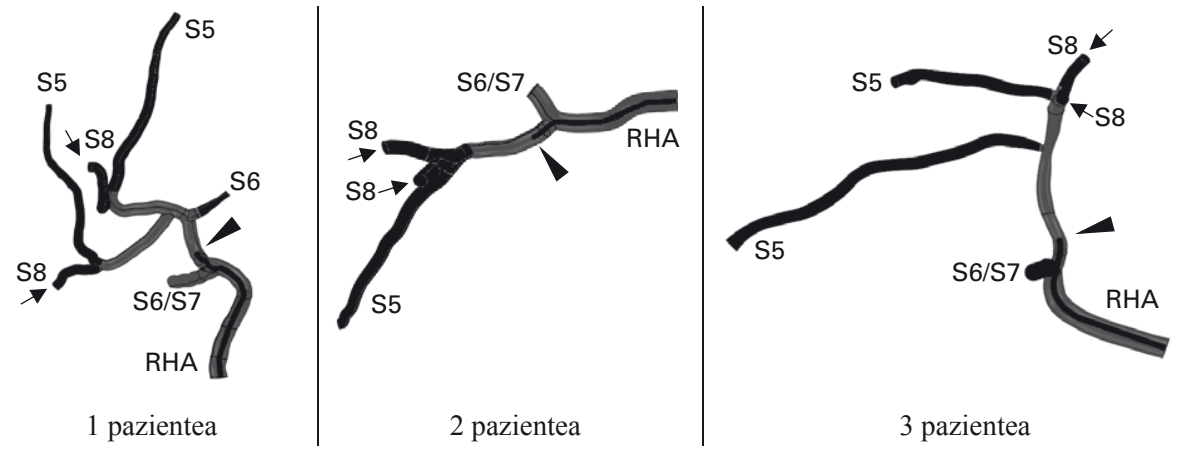

2. irudia. Hiru pazienteen arteria hepatiko sare moztuak. RHA: Eskuin Arteria Hepatikoa (ingelesez: Right Hepatic Artery). Gezi-buruek mikrokateterraren kokapena adierazten dute. Geziek tumoredun segmentuetara doazen adarrak adierazten dituzte.

Ikerketa honetan erabilitako eredu matematikoa Aramburu et al.-ek planteatutakoa da [4]. Laburbilduz, arteria hepatikoko hemodinamika eta injektatutako mikroesferen garraioa kalkulatuko dira. Horretarako, odola fluido isotermo eta konprimaezina dela jo da, fluxua erregimen laminarrean aztertuz eta jarrera ez-newtondarra izanik aztergai. Mikroesferen gain eragiten duten indarren inguruan, grabitate-indarra, presio-gradientearen indarra, herrestatze-indarra eta masa birtualaren indarra izan dira kontuan. Odolaren biskositatea ez-newtondar gisa aztertzean, Quemada biskositate eredua erabili da [8]. Newtondar gisa aztertzean, ordea, ebakidura-esfortzua handitzean lortzen den biskositate-balio konstantea finkatu da, hots, 0,00309 $\mathrm{Pa} \cdot \mathrm{s}$.

Ordenagailu bidezko kalkuluak egin ahal izateko, lehenik, geometria tridimentsionala bolumen txikitan zatitu behar da: diskretizazio-proze- 
sua. Bolumen txikitan zatitutako geometriari sare deitzen zaio. Aztertutako geometria guztien sareak prozedura bera erabiliz garatu dira. Horretarako Fluent Meshing 2020R1 (ANSYS Inc., Canonsburg, PA, USA) softwarea erabili da. Sarea garatzeko erabilitako elementuak poliedro-hexaedro motakoak izan dira, elementu mota horrek geometria konplexuetara egokitzeko duen erraztasunagatik eta beste elementu mota batzuekin alderaturik duen elementu kantitate txikiagoagatik. Sarearen elementu bakoitzaren, hots, bolumen txiki bakoitzaren, neurri maximoa 0,2 mmkoa eta minimoa 0,02 mm-koa dira arterian zehar. Mikrokateterra ordea, 0,05 mm-ko elementutan zatitu da. Azkenik, pareta inguruko fluxua egoki modelizatu ahal izateko, 4 geruzako inflazio-geruza bat sortu da, lehen geruzaren lodiera 0,01 mm-koa izanik, 1,1-eko hazkunde-ratioarekin. Geometria bakoitzak, batez beste, 0,8 milioi elementu ditu. Ondoren, muga-baldintzak definitzen dira: sarrera eta irteeretako abiadura edo presioak, eta paretetako baldintzak. Azkenik, injektatuko diren mikroesferen ezaugarriak finkatzen dira: kopurua, materiala, tamaina, injekzio-abiadura, eta abar. Aldagai horiek guztiak Aramburu et al. lanean definitu bezala gauzatu dira [4].

Odolaren biskositatearen eragina aztertzeko bi aldagai aztertu dira. Alde batetik, modu kuantitatibo batean aztertuz, injektatutako mikroesferak zein segmentutara iritsi diren aztertu da. Era horretara, biskositate aldakorretik konstantera pasatzean gerta daitezkeen mikroesferen ibilbideen aldaketak aztertu dira. Bestalde, modu kualitatibo batean aztertuz, mikrokateter-puntaren zeharkako planoko fluxu-patroiak aztertu dira abiaduraren magnitude eta bektoreak aztertuz. Era horretara, biskositate-aldaketaren ondorioz hemodinamikan gerta litezkeen aldaketak ikusi nahi dira.

\subsection{Emaitzak}

Esan bezala, lortu diren emaitzak bai kuantitatiboki eta bai kualitatiboki aztertuko dira. Emaitza kuantitatiboei dagokienez, mikroesferen segmentuz segmentuko banaketak alderatu dira aztertutako 3 pazienteetan. Hau da, injektatutako mikroesferak zein «irteera»tara iritsi diren ikertu da. 3. irudian ikus daitekeen bezala, eredu newtondarretik ez-newtondarrerako ezberdintasunak txikiak dira, diferentzia handiena \% 0,5-ekoa izanik. Zehatzago aztertuz, 1 pazientean mikroesferak 5, 6 eta 8 segmentuetara iristen dira, eredu batetik besterako aldea $\% 0,1, \% 0$ eta $\% 0,1$ izanik hurrenez hurren. 2 pazienteari dagokionez, mikroesfera guztiak 8 segmentura heltzen dira bi kasuetan (\% 0ko aldea). Eta 3 pazienteari dagokionez, 5 eta 8 segmentuetara iristen dira mikroesferak, \% 0,5-eko aldearekin bi segmentuetan. 
Unai Lertxundi, Jorge Aramburu, Raúl Antón, Jose Ignacio Bilbao, Macarena Rodríguez-Fraile, Bruno Sangro



3. irudia. Segmentuz segmentuko mikroesfera-banaketak pazienteka.

Analisi kualitatiboari dagokionez, abiadura-inguruak eta abiadura-bektoreak aztertu dira paziente bakoitzean, eredu newtondarraren emaitzak ez-newtondarrarekin alderatuz. Aldagai horiek mikrokateterraren puntaren zeharkako planoan aztertu dira. Bestalde, abiaduraren balioa denboran zehar aldatzen denez (ikus 4. irudia ziklo kardiako batentzat), emaitzak aztertuko diren denbora-unea ere finkatu beharra dago. Emaitzak ziklo kardiakoaren bi denbora-une esanguratsutan aztertzea erabaki da: sistolearen puntan, non odolaren abiadura maximoa den, eta diastolearen amaieran, non abiadurak balio baxuenetarikoa hartzen duen eta zikloaren amaiera den.

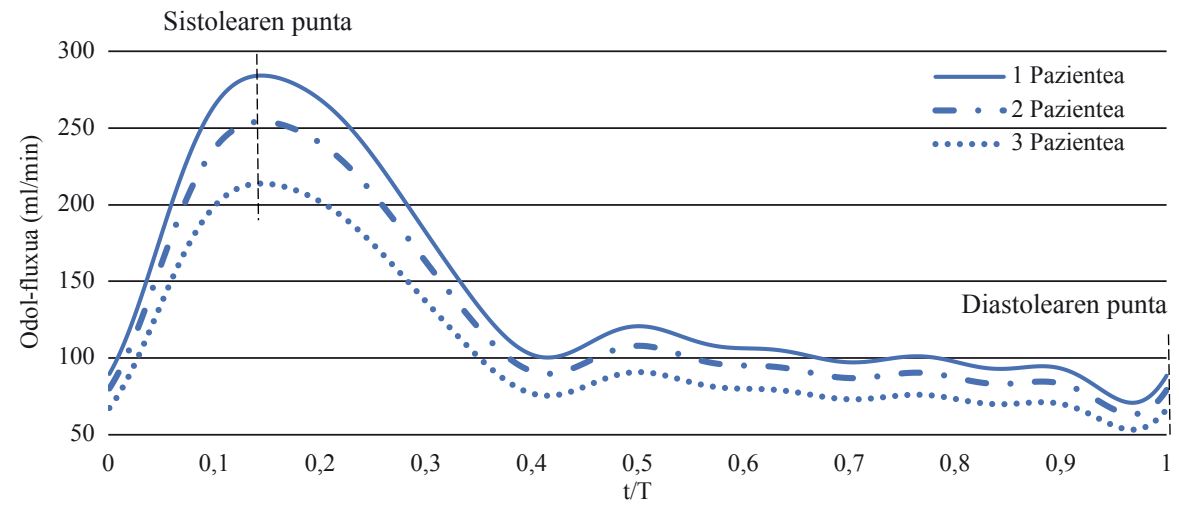

4. irudia. Sarrerako odol-fluxua (inposatutako ziklo kardiakoa). Sistolearen punta $(\mathrm{t} / \mathrm{T}=0,15, \mathrm{~T}=1 \mathrm{~s})$ eta diastolearen amaiera $(\mathrm{t} / \mathrm{T}=1, \mathrm{~T}=1 \mathrm{~s})$ dira emaitzak aztertuko diren puntuak. 
Emaitza kualitatiboei dagokienez, ez da fluxu-patroian aldaketarik nabari eredu batetik bestera (ikus 5 . irudia). Hori dela eta, fluidoak jasaten dituen biskositate-aldaketak fluxuan duten eragina mespretxagarria dela ondorioztatzen da. Abiadurak mikrokateterra kokatua dagoen planoan aztertu direnez, 5. irudiko kasu bakoitzean azaltzen den abiadura baxuko eraztuna mikrokateterraren muturreko pareta da; hori dela eta, bertako abiaduraren balioa zero da. Eraztun horren barruko gunea mikrokateterretik txertatutako fluxua da. Gainerako guztia arteriatik datorren odol-fluxua da.



5. irudia. Abiaduraren magnitudearen inguruak eta bektoreak. Irudi honetan, dezimaletarako puntua («.») erabili da, komaren partez («,»). 
Unai Lertxundi, Jorge Aramburu, Raúl Antón, Jose Ignacio Bilbao, Macarena Rodríguez-Fraile, Bruno Sangro

Bai 3. eta bai 5. irudietan aurkeztutako emaitzetan, aldeak nabari dira paziente batetik bestera. Alde horiek geometria ezberdinak izatearen ondorio zuzena dira. Odol-fluxua arterian zehar doan heinean, inertzia hartuz doa arteriak duen formaren baitan (kurbak, adibidez). Esate baterako, gorputz bat txirrista batetik botatzen bada, kurba bat hartzean alde batera gerturatuko da. Gauza bera gertatzen zaio odolari arterietan zehar. Hori dela eta, geometriak ezberdinak direnez, abiadurak ere ezberdinak dira paziente bakoitzean. Adibidez, abiadura altuagoko puntuak irudiaren beheko aldean azal litezke (ikus 5. irudia, 1 pazientea), beste batzuetan goikoan ikusten dira (ikus 5. irudia, 2 pazientea), edo baita alde batean ere (ikus 5. irudia, 3 pazientea).

Emaitza hauetan ez da aztertu tratamenduaren eraginkortasuna - ea mikroesferak tumoreak dituen segmentura bideratu diren ala ez- eta ezin izan da modu alderagarri batean neurtu simulazioek behar izan duten denbora. Dena den, eredu newtondarra erabiltzean ekuazio bat gutxiago ebatzi behar da, Quemadaren ereduaren ekuazioa, hain zuzen ere. Frogatu egin beharko litzatekeen arren, uste dugu eredu newtondarraren erabilerarekin simulazio-denbora murriztu egiten dela eredu ez-newtondarra erabiltzen duen kasuarekin alderatuta.

Azkenik, emaitzak balioztatu beharko lirateke. Izan ere, nahiz eta odolaren portaera newtondarraren eta ez-newtondarraren artean ezberdintasunik ia ez dagoen, emaitza hauek errealitatea islatzean dutela ziurtatu beharra dago. Horretarako simulazio bidez lortutako mikroesfera-banaketak errealitatean gauzatutako ebakuntzarekin alderatu beharko lirateke. Hori Antón et al.-ek balioztatu dute berriki [9]. Lan honetan aztertutako kasuetako arteria-sareak benetako paziente batzuenak badira ere, sortu diren minbizi-egoerak fikziozkoak dira. Hortaz, kasu jakin honetan ezin daiteke konparazioa garatu.

\section{ONDORIOAK}

Emaitzak aztertzeko garaian, mikroesferen segmentuz segmentuko banaketan eta odolaren hemodinamikan (mikrokateter-puntaren zeharkako planoko fluxu-patroietan) jarri da arreta. Kuantitatiboki azterturik, mikroesferen banaketari dagokionez, alderik handiena \% 0,5-ekoa da. Balio hori guztiz onargarritzat hartzen da. Bestalde, kualitatiboki azterturik, fluxu-patroien artean ez da inongo ezberdintasunik ikusi. Lortutako emaitzen arabera, mikroesferen banaketari eta odolaren hemodinamikari dagokienez jarrera ez-newtondarraren eragina mespretxagarria dela ondorioztatu da, ez baita ezberdintasunik nabari modelo batetik bestera. Hortaz, odola fluido newtondartzat jotzean egiten den sinplifikazioa ontzat hartzen da. Dena den, erradioenbolizazioaren kasurako eredu newtondarra erabil 
badaiteke ere, ondorio hau ezin daiteke orokortu. Adibidez, oso arteria txikietan edo odol-fluxua asko murrizten den kasuetan eredu ez-newtondarra erabili beharko da.

\section{ETORKIZUNERAKO PLANTEATZEN DEN NORABIDEA}

Ikerketa-lerro honen helburu nagusia paziente bakoitzari egokitutako erradioenbolizazio-tratamendua garatzea da. Tratamendu honetan aldagai ugari finkatu behar dira, hala nola erabiliko den mikrokateter eta mikroesferak, mikrokateterraren kokapena, mikroesferen injekzio-abiadura, eta abar. Aldagai horietako asko ordenagailu bidezko CFD simulazioen bidez finka daitezke zuzenean. Gainera, paziente bakoitzari egokitua dela ziurtatzeko, bakoitzaren arteria-sarearen kopia digital batean gauzatzen dira beharrezkoak diren kalkuluak. Metodo hori erabilgarria izan dadin, prozesu osoaren iraupena (gaixoaren gibelaren irudia hartzetik tratamendua planteatu artekoa) ordu gutxi batzuetara murriztu beharra dago, kalkuluetan erabiliko den gibelaren irudia (hau da, arteria-sareak, tumoreen kokapen eta neurriak) alda ez dadin prozesuak irauten duen bitartean.

Gaur-gaurkoz, prozesu honen iraupena luzeegia da oraindik. Kalkuludenbora gutxitu ahal izateko eredua sinplifikatu beharra dago. Hori dela eta, azken ikerketak, artikulu hau barne, ildo honetan ari dira lanean. Bestalde, lan ugari geratzen da oraindik. Bide ezberdinak daude helburua lortu ahal izateko: geometrian eginiko sinplifikazioak [3], kalkulu matematikoen sinplifikazioa (artikulu hau bera), 3D-tik 1D / 0D-ko ereduetara sinplifikatzea, eta abar. Dena den, sinplifikazio bakoitzak zehaztasuna mantentzen duela ziurtatu beharra dago; adibidez, simulazioen emaitzak benetako pazienteen emaitzekin alderaturik, errealitatea irudikatzen duen erreminta garatzen dela egiaztatzeko.

\section{ESKER ONAK}

Autoreek Cátedra Fundación Antonio Aranzábal - Universidad de Navarraren laguntza eskertu nahi dute. U. Lertxundik bere esker ona aitortu nahi dio Eusko Jaurlaritzako Hezkuntza Sailari «Doktore ez diren ikertzaileak prestatzeko Doktoratu Aurreko Programako laguntza»ren bidez emandako laguntza ekonomikoagatik.

\section{BIBLIOGRAFIA}

[1] Bray, F., Ferlay, J., Soerjomataram, I., Siegel, R. L., Torre, L. A., JeMAL, A. 2018. «Global cancer statistics 2018: GLOBOCAN estimates of in- 
Unai Lertxundi, Jorge Aramburu, Raúl Antón, Jose Ignacio Bilbao, Macarena Rodríguez-Fraile, Bruno Sangro

cidence and mortality worldwide for 36 cancers in 185 countries». CA: A Cancer Journal for Clinicians, 68, 394-424.

[2] Childress, E. M., Kleinstreuer, C. 2014. «Impact of Fluid-Structure Interaction on Direct Tumor-Targeting in a Representative Hepatic Artery System». Annals of Biomedical Engineering, 42, 461-474.

[3] Lertxundi, U., Aramburu, J., Ortega, J., Rodríguez-Fraile, M., Sangro, B., BilbAO, J. I., ANTÓN, R. 2021. «CFD Simulations of Radioembolization: A Proof-of-Concept Study on the Impact of the Hepatic Artery Tree Truncation». Mathematics 2021, Vol. 9, Page 839, 9, 839.

[4] Aramburu, J., Antón, R., Rivas, A., Ramos, J. C., Sangro, B., Bilbao, J. I. 2017. «Computational particle-haemodynamics analysis of liver radioembolization pretreatment as an actual treatment surrogate». International Journal for Numerical Methods in Biomedical Engineering, 33, e02791.

[5] Basciano, C. A., Kleinstreuer, C., Kennedy, A. S., Dezarn, W. A., ChilDRESS, E. 2010. «Computer Modeling of Controlled Microsphere Release and Targeting in a Representative Hepatic Artery System». Annals of Biomedical Engineering, 38, 1862-1879.

[6] Roncali, E., Taebi, A., Foster, C., Vu, C. T. 2020. «Personalized Dosimetry for Liver Cancer Y-90 Radioembolization Using Computational Fluid Dynamics and Monte Carlo Simulation». Annals of Biomedical Engineering, 48, 1499-1510.

[7] Couinaud, C. 1992. «The anatomy of the liver». Annali italiani di chirurgia, 63, 693-697.

[8] Buchanan, J. R., Kleinstreuer, C., Comer, J. K. 2000. «Rheological effects on pulsatile hemodynamics in a stenosed tube». Computers and Fluids, 29, 695-724.

[9] Antón, R., Antoñanas, J., Aramburu, J., Ezponda, A., Prieto, E., AnDonegui, A., Ortega, J., Vivas, I., SAncho, L., SAngro, B., Bilbao, J. I., RODRÍGUEZ-FrAILE, M. 2021. «A proof-of-concept study of the in-vivo validation of a computational fluid dynamics model of personalized radioembolization». Scientific Reports. 